\title{
A DUPLICATA VIRTUAL E O BOLETO BANCÁRIO - EFEITOS DA INFORMÁTICA SOBRE OS TÍTULOS DE CRÉDITO
}

\author{
THE TRADE ACCEPTANCE BILL AND BANK INVOICES - EFFECTS OF INFORMATION \\ TECHNOLOGY ON THE NEGOTIABLE INSTRUMENTS
}

Tarcisio Teixeira*

\begin{abstract}
Resumo:
$\mathrm{O}$ presente artigo tem por fim estudar a influência da informática sobre os títulos de crédito, objetivando verificar a possibilidade de reconhecimento jurídico dos títulos emitidos eletronicamente como documentos, bem como a viabilidade de sua execução judicial em havendo inadimplência. Para tanto, analisaremos os princípios da cartularidade e da literalidade, a duplicata virtual e o boleto bancário, além dos aspectos práticos e processuais inerentes aos títulos de crédito.
\end{abstract}

Palavras-chave: Título de crédito eletrônico. Título emitido eletronicamente. Documento eletrônico. Duplicata virtual. Boleto bancário.

\begin{abstract}
:
This paper aims to study the influence of information technology on the negotiable instruments, in order to verify the possibility of legal recognition of the instruments issued as electronic ones, as well as the feasibility of the judicial enforcement in case of default. We will analyze the documentary evidence and the literal transcript principles, and virtual trade acceptance bills, besides practical and procedural aspects about negotiable instruments.
\end{abstract}

Keywords: Electronic negotiable instruments. Electronic instruments. Digital instruments. Virtual trade acceptance bills. Bank invoices.

Introdução

Este trabalho visa analisar a influência da informática sobre os títulos de crédito, sobretudo em relação à duplicata, objetivando verificar a possibilidade de reconhecimento jurídico dos títulos emitidos eletronicamente como documentos e a viabilidade de sua execução judicial em caso de inadimplência. Para tanto, faremos uma introdução à problemática.

Primeiramente, vale ter em conta que a palavra "crédito" vem do latim credere e significa confiar, confiança. Por isso, o crédito oferece a possibilidade de

\footnotetext{
* Doutor e Mestre em Direito Comercial pela Faculdade de Direito da Universidade de São Paulo. Professor de Direito Empresarial da Universidade Estadual de Londrina (UEL). Contato: tarcisioteixeira@ tarcisioteixeira.com.br.
} 
aquisição imediata pelo seu tomador em relação à compra de produto ou de serviço e à espera do vendedor para receber a contraprestação pelo que vendeu.

Com isso, o crédito possibilita a circulação de riquezas sem a necessidade do pagamento imediato. Assim, cuida-se da troca de uma prestação atual por uma prestação futura com base na confiança de uma parte na outra. Assim, de forma singela, título de crédito é um documento que representa um direito do credor contra o devedor de uma obrigação.

Pode-se dizer que o dinheiro é uma forma de troca aceita por todos. É o método para adquirir mercadorias e serviços. Porém, anteriormente, as negociações eram feitas por trocas in natura (de coisa por coisa); mais tarde, passou-se a usar o sal como moeda; depois a moeda-metálica; e, finalmente, o papel-moeda fundado na confiança do Estado emissor. Passou-se da chamada economia natural para a economia monetária, caracterizada pela moeda como instrumento de troca. Posteriormente, a economia monetária cedeu lugar, de forma parcial, à economia creditória, ampliando o conceito de troca, ou seja, o dinheiro em espécie foi, em parte, substituído pelos títulos de crédito.

Os títulos de créditos surgiram na Idade Média como instrumento para facilitar a circulação do crédito comercial. O primeiro título de crédito inventado foi a letra de câmbio. A princípio, o título de crédito foi criado como uma forma de contrato de câmbio para o trajeto, ou seja, uma forma de segurança encontrada para evitar que os títulos dos mercadores fossem subtraídos durante suas viagens. Depois, com o passar do tempo, o título de crédito assume a condição de representar valores, contendo implicitamente a obrigação de realizar esse valor no prazo convencionado.

Quanto ao conceito de título de crédito, classicamente utiliza-se o conceito formulado pelo italiano Cesare Vivante como o "documento necessário para o exercício do direito literal e autônomo nele mencionado".

O Código Civil, de 2002, influenciado pelo Direito italiano, no seu art. 887, trouxe um conceito de título de crédito, que é semelhante ao de Cesare Vivante: "O título de crédito, documento necessário ao exercício do direito literal e autônomo nele contido, somente produz efeito quando preencha os requisitos da lei".

Feito esse preâmbulo, vale ter em conta que, são inegáveis os efeitos que o Direito tem recebido em decorrência do desenvolvimento da tecnologia da informação, como a criação do comércio eletrônico e os inúmeros contratos praticados naquele ambiente; o sistema de pregão eletrônico da Bolsa de Valores; o cumprimento das obrigações tributárias acessórias por meio da internet e a criação do SPED - Sistema Público de Escrituração Digital - e da NF-e - Nota Fiscal Eletrônica; entre outros.

Especificamente no campo dos títulos de crédito, a informática também vem trazendo mudanças importantes há algumas décadas, como será visto quanto à duplicata, por exemplo. Mas o tema ganhou relevo com a vigência do Código Civil, de 
2002, especialmente pelo $\S 3^{\circ}$ do art. 889 , o qual prevê a possibilidade da emissão de título por computador. ${ }^{1}$

A emissão de título de crédito por computador tem recebido a denominação título de crédito eletrônico ou virtual, ou seja, é o título emitido por meio eletrônico, não materializado em papel (o título é real, mas não é impresso em papel). Esse fato pode ser tido como uma exceção ao princípio cambiário da cartularidade. Além disso, pode trazer implicações para a execução judicial do credor contra o devedor e coobrigados.

Com o fim de aprofundarmos o estudo, a presente pesquisa será delimitada pela análise dos efeitos da informática aos títulos de crédito típicos ou sentido estrito, isto é, aqueles que foram emitidos em razão de uma aquisição imediata de bens ou serviços mediante o pagamento do preço no futuro, como no caso da duplicata. Portanto, escapa do objeto desta pesquisa a análise de outros títulos, como os valores mobiliários (emitidos em série/massa ${ }^{2}$ ), entre os quais estão as ações de sociedade anônima; os títulos ao portador (obrigação de fazer), como bilhetes de ônibus; títulos representativos (representam mercadorias ou garantias), como certificado de depósito agropecuário e o warrant agropecuário.

1. Os princípios da cartularidade e da literalidade estão em jogo?

Cartularidade deriva de "cártula", cujo significado é papel; logo, um título de crédito deveria ser firmado em papel, a priori. Vale destacar que os títulos de crédito desde a sua criação na idade média se desenvolveram materializados em papel; por isso, o princípio ter recebido a denominação "cartularidade". Assim, é necessário perquirir quais são os efeitos que a informática traz à teoria dos títulos de crédito, e, neste particular, ao princípio da cartularidade.

Este dispositivo foi acrescido ao então projeto de Código Civil por força de Mauro Rodrigues Penteado, professor de Direito Comercial da Faculdade de Direito do Largo São Francisco - USP. Vale lembrar que, a parte do projeto de Código Civil, hoje em vigor, que trata de títulos de crédito se deu por obra do saudado professor de Direito Comercial Mauro Brandão Lopes, o qual pertenceu à mesma academia jurídica. Este último vislumbrava que a partir de tais regras seria possível a criação de títulos atípicos. O aprofundamento dessa discussão escapa do objeto deste trabalho, mas não podemos deixar de mencionar que não são poucos os que sustentam a impossibilidade da criação destes títulos, haja vista a insegurança que seria produzida a partir disso, podendo ser citados exemplificativamente: COMPARATO, Fábio Konder. Ensaios e pareceres de direito empresarial. Rio de Janeiro: Forense, 1978. p. 548-550; e DE LUCCA, Newton. Aspectos da teoria geral dos títulos de crédito. São Paulo: Pioneira, 1979. p. 121-127.

Apesar de aderirmos a tese da possibilidade de criação de títulos atípicos, a partir do Código Civil vigente, pensamos que os empresários até hoje não o fizeram principalmente pelo fato de que, se houver inadimplência, o documento não será considerado como título executivo extrajudicial, face à falta de previsão legal.

2 BULGARELLI, Waldirio. Títulos de crédito. 2. ed. São Paulo: Atlas, 1982. p. 85-88. 
Teoricamente, em razão da expressão "cartularidade", o título de crédito não poderia ser materializado em outro suporte que não o papel (o que não é verdade), como, por exemplo, em tecido, madeira, couro, vidro etc. Se assim fosse, o mais apropriado, então, seria chamar esse princípio de princípio da materialidade ou, melhor ainda, princípio da documentalidade, e não da cartularidade.

Mas isso vem sendo cada vez mais discutido, principalmente, a partir da vigência do art. $889, \S 3^{\circ}$, do Código Civil, ao prever a possibilidade da emissão de título por computador. Dessa forma, emitido eletronicamente, não sendo materializado em papel, seria uma exceção ao princípio da cartularidade.

Pelo princípio da cartularidade, o exercício do direito (literal e autônomo) representado por um título de crédito pressupõe a sua posse, pois somente quem exibe a cártula (o papel, que representa o título) pode exigir a satisfação do direito que está documentado no título. Assim, em geral, quem não tem a posse do título não pode ser presumido credor. Para Newton De Lucca cartularidade significa a necessidade de apresentação do documento para o exercício do direito. ${ }^{3}$

Com isso, para instruir a petição inicial de uma execução judicial, é necessária a exibição do original, não podendo ser cópia autenticada. Dessa forma, tem-se a garantia de que quem postula a satisfação do direito é realmente o seu titular, o que dá segurança às operações creditórias.

A necessidade da cártula original evita o enriquecimento sem causa de oportunistas, como hipoteticamente alguém que já foi credor daquele título, mas agora não é mais por tê-lo transferido a outra pessoa.

Se fosse possível ajuizar a execução anexando uma cópia do título, o original poderia continuar circulando, prejudicando terceiros de boa-fé. Uma exceção a isso (e ao princípio da cartularidade) ocorre quando o devedor não devolve a duplicata (que lhe foi enviada para aceitação). Nesse caso, a execução pode ser instruída com o comprovante de entrega da mercadoria, pois o título original foi retido pelo devedor.

É preciso ter em mente que, sem sombra de dúvida a informática tem promovido a substituição do papel em muitas áreas, sendo que no Direito, especialmente no Direito Comercial, isso não é diferente. A informática tem implicado cada vez mais na virtualização das operações mercantis, afetando também o princípio da cartularidade.

No clássico e difundido conceito de Vivante, bem como no do art. 887 do Código Civil, não se exige que o título esteja firmado em papel, menciona-se apenas a expressão "documento" não "cártula". Isso, porque, documento teoricamente pode ser materializado em vários tipos de suporte: papel, tecido, couro, vidro, etc. E como será

DE LUCCA, Newton. Aspectos da teoria geral dos titulos de crédito. cit., p. 57. 
visto adiante um arquivo digital ou eletrônico é tido como um documento, sendo que nosso ordenamento, a propósito, reconhece a validade do documento eletrônico.

Tullio Ascarelli, ao tratar da teoria geral dos títulos de crédito, situa o título de crédito como um documento, mas não necessariamente documento cartular. ${ }^{4}$

Por sua vez, Frabrizio Devescovi chama a atenção quanto ao suporte dos títulos de crédito mencionando que, não se trata de desmaterializar o título, mas de descartularizá-lo, pois apenas substitui-se o meio cartular por outro veículo. ${ }^{5}$

Quanto ao princípio da literalidade, "literal" quer dizer que vale apenas o que está escrito, ou seja, o que efetivamente está estampado no título. Assim, somente produzem efeitos jurídico-cambiários os atos lançados no próprio título de crédito, pois apenas o conteúdo do título é que possui valor cambiário.

Os atos firmados em documentos separados entre as partes, ainda que válidos entre elas, não irão produzir efeitos perante os terceiros. É o caso do recibo separado, que não produz consequência jurídica perante o terceiro de boa-fé que recebeu o título, pois este não sabia que o título tinha sido quitado devido ao fato de não constar a quitação no corpo do título de crédito. Logo, a quitação deve constar no próprio título. No caso de pagamento parcial, quem paga apenas uma parte de um título deve exigir a quitação parcial no corpo do título, para evitar a transmissão pelo valor total a terceiro de boa-fé.

Outro exemplo é o aval (garantia dada em títulos de crédito, que apenas é válido se constar no corpo do título ou folha anexa, pois, do contrário, será considerado inexistente (art. 31 do Decreto n. 57.663, de 24 de janeiro de 1966 - conhecido como Lei Uniforme - LU).

Como discorremos adiante, em teoria, mediante o uso da tecnologia da informação, especialmente com o recurso da assinatura digital e certificação eletrônica (temas que serão examinados adiante), um arquivo pode ter sua literalidade preservada. A assinatura digital visa assegura a autenticidade do documento, o que não prejudicaria o princípio da literalidade. Assim, como bem apontado por Raphael Velly de Castro, o requisito da assinatura no corpo do próprio título será atendido mediante esse recurso tecnológico (assinatura digital). ${ }^{6}$

ASCARELLI, Tullio. Teoria geral dos títulos de crédito. 2. ed. São Paulo: Saraiva, 1969. p. 61-63.

DEVESCOVI, Frabrizio. Titolo di credito e informática. Padova: Cedam. 1991. Le monografie di Contratto e Impresa - serie diretta da Francesco Galgano. p. 97 apud GARDINO, Adriana Valéria Pugliesi. Títulos de crédito eletrônicos: noções gerais e aspectos processsuais. In: PENTEADO, Mauro Rodrigues (Coord.). Títulos de crédito: teoria geral e títulos atípicos em face do novo Código Civil, títulos de crédito eletrônico. São Paulo: Walmar, 2004. p. 18.

6 CASTRO, Raphael Velly de. Notas sobre a circulação e a literalidade nos títulos de crédito eletrônicos. In: PENTEADO, Mauro Rodrigues (Coord.). Títulos de crédito: teoria geral e títulos atípicos em face do novo Código Civil, títulos de crédito eletrônico. São Paulo: Walmar, 2004. p. 397-398. 
2. A informática e os títulos de crédito

Como já apontado, o art. $889, \S 3^{\circ}$, do Código Civil prevê a possibilidade da emissão de título por computador. Essa emissão tem recebido a denominação título de crédito eletrônico ou virtual. Alguns defendem que essa emissão eletrônica de um título de crédito somente seria possível para a duplicata, haja vista que ela é um título emitido pelo próprio credor.

É preciso investigar se o fato de um título ser emitido eletronicamente feriria o princípio da cartularidade, ou seria mais uma exceção a ele, como é o caso da duplicata. A Lei de Duplicatas, no seu art. 13, $\S 1^{\circ}$, prevê a possibilidade do protesto por indicação, sem a duplicata original quando não devolvida pelo credor. Por esse mandamento legal, é possível realizar um ato cambiário, o protesto, sem o absolutismo quanto ao princípio da cartularidade.

Desse modo, a previsão do Código Civil poderia ser outra hipótese de exceção ao princípio da cartularidade, inclusive levando-se em consideração que as situações, os princípios e as normas evoluem. E os títulos de crédito estão acompanhando a evolução da sociedade, da ciência e do comércio. Muitas negociações têm sido estabelecidas eletronicamente, por isso, nada mais óbvio do que a possibilidade de emissão de títulos eletrônicos.

Quanto à assinatura do emitente, à possibilidade de circulação e à segurança dos títulos eletrônicos, este poderá ser garantido pelos sistemas de assinatura eletrônica e certificação digital, que no Brasil é disciplinado pela Medida Provisória n. 2.2002/2001, que criou a Infraestrutura de Chaves Públicas Brasileira - ICP-BRASIL -, a qual trataremos a seguir.

A desmaterialização dos títulos de crédito não é algo novo. Como bem ponderou Newton De Lucca, pioneiro no trato da questão no Brasil, esse fato teve início em França, no ano de 1967, quando se passou a utilizar uma letra de câmbio que não era materializada. Nesse caso, o comerciante passou a remeter seus créditos ao banco por meio de fitas magnéticas, acompanhadas de um borderô de cobrança, não existindo nem circulação do título, ${ }^{7}$ nem sua tradicional materialização do ponto de vista da cartularidade.

Michel Vasseur, ao analisar o fenômeno dos efeitos da informática sobre os títulos de crédito em França, no final da década de 1960, apontou que ao se considerar o título de crédito como um suporte de informação, o papel não é indispensável, podendo ser substituído por um suporte magnético. ${ }^{8}$

DE LUCCA, Newton. A cambial-extrato. São Paulo: Revista dos Tribunais, 1985. p. 23 e ss.

8 VASSEUR, Michel. Letra de câmbio-reprodução. Da influência da informática sobre o direito. Revue Trimestrielle de Droit Commercial, abr.jun. 1975. p. 08 e ss. Apud Nelson Abrão. Cibernética e títulos de 
Sobre a discussão da possibilidade ou não da criação de títulos de crédito atípicos pela via eletrônica, talvez o mais apropriado não fosse chamá-lo "título de crédito eletrônico", mas, sim, "título de crédito emitido eletronicamente", pois o que será obtido é um título já previsto no ordenamento jurídico (por exemplo, a duplicata), mas agora emitido em suporte eletrônico, e não mais em papel.

Destaca-se que a própria redação do $\S 3^{\circ}$, do art. 889 , do Código Civil, quando menciona computador ou meio técnico equivalente, está tratando da forma de emissão dos títulos, e não da criação de novos títulos de crédito.

Examinando a questão, Fernando Netto Boiteux afirma que meio eletrônico é qualquer meio de armazenamento ou de comunicação de dados por via eletrônica, sendo esse meio apto para uma pessoa poder externar sua vontade, o que se configurará em um documento, que por sua vez poderá ser um título de crédito perfeitamente válido. ${ }^{9}$

Ainda com referência à materialização do título, o princípio da cartularidade, na expressão "documento necessário" do conceito de título de crédito, tem a finalidade primordial de provar a existência do crédito, uma vez que, até algumas décadas atrás o papel era o suporte que se tinha como mais apropriado para a firmação do crédito, o seu exercício em termos de transmissão e cobrança, e a respectiva perícia em caso de dúvida.

Com a evolução da tecnologia, tudo isso (confirmação da existência do crédito e sua transmissão, cobrança etc.) poderá ser feito utilizando-se o suporte eletrônico. O Direito não pode se esquivar ao avanço tecnológico da sociedade e do comércio.

Os problemas advindos de oportunistas e falsificadores no ambiente eletrônico não são menores que os de fora desse ambiente. Os sistemas de assinatura digital e de certificação digital (com codificação por meio de sistema criptográfico assimétrico e uso de chave pública e privada), a propósito, podem ser mais seguros do que a sistemática de assinatura e reconhecimento de firma por semelhança dos cartórios brasileiros; ou até mesmo pela assinatura de duas testemunhas.

\section{Duplicata virtual e boleto bancário}

Antes do exame efetivo das influências da informatização sobre a duplicata, enquanto título de crédito, é preciso resgatar um pouco de suas regras gerais, objetivando uma melhor compreensão da duplicata virtual.

crédito. Revista de Direito Mercantil, Industrial, Econômico e Financeiro. São Paulo: Revista dos Tribunais, n. 19. 1975. p. 95.

9 BOITEUX, Fernando Netto. Títulos de crédito: (em conformidade com o novo código civil). São Paulo: Dialética, 2002. p. 46. 
Duplicata mercantil é o título de crédito criado a partir de uma compra e venda mercantil, sendo emitida pelo vendedor contra o comprador, que efetuará o pagamento. Também é possível a emissão de duplicata de prestação de serviços quando o objeto for a realização de uma prestação de serviços, não uma compra e venda mercantil.

Diferentemente do cheque, da nota promissória, da letra de câmbio e de outros, a duplicata é um título de crédito de criação brasileira, cuja emissão é realizada pelo credor do título. A palavra "duplicata" tem origem no revogado art. 219 do Código Comercial, ao disciplinar a entrega da fatura "por duplicado" (uma via ficava para o comprador e outra para o vendedor).

O devedor (principal) da duplicata é o sacado, que é o comprador; porém este não é o emitente do título, mas sim o credor. O regime jurídico da duplicata é a Lei n. 5.474/68 - Lei da Duplicata - LD -, aplicando-se o Decreto n. 57.663/66 - Lei Uniforme - no que couber em matéria de emissão, circulação e pagamento (LD, art. 25), além dos princípios do direito cambiário (cartularidade, literalidade, autonomia etc.) e regras sobre aval, vencimento etc.

Teoricamente, o aceite na duplicata é obrigatório: ela deve ser enviada pelo vendedor ao comprador para que este faça o aceite (LD, art. $6^{\circ}$ e ss.). No entanto, na prática, os vendedores acabam por enviar juntamente com a nota fiscal-fatura um boleto para quitação via bancária, não cumprindo assim a duplicata seu trâmite normal e burocrático previsto na lei.

Na duplicata, o aceite pode ser ordinário: se dá pela assinatura do aceitante (comprador) no título; por comunicação: quando o comprador retém o título, mas efetua um aviso comunicando (por exemplo, pela troca de e-mails); por presunção: quando não há causa para recusa do aceite, e, nesse caso, o comprador assina o canhoto da nota fiscalfatura referente ao recebimento das mercadorias.

Acerca do protesto da duplicata, vale mencionar que conforme a Lei do Protesto - Lei n. 9.492/97; art. $1^{\text {o: }}$ "Protesto é o ato formal e solene pelo qual se prova a inadimplência e o descumprimento de obrigação originada em títulos e outros documentos de dívida".

À luz da Lei da Duplicata, o protesto da duplicata pode ocorrer pela falta de pagamento, falta de devolução do título ou pela falta de aceite (LD, art. 13, caput). O credor que não efetuar o protesto no prazo de trinta dias do vencimento perde o direito de regresso contra os coobrigados - endossantes e avalistas (LD, art. 13, $\S 4^{\circ}$ ). É importante destacar que a Lei de Protesto menciona que não cabe ao Tabelião o exame de datas do título, existindo, dessa forma, um conflito aparente de normas (Lei n. 9.492/97, art. $9^{\circ}$ ).

Como regra geral, é necessário o título de crédito original para efetuar o seu protesto. Mas, no caso de duplicata, se o comprador não devolveu o título, poderá se realizar o protesto por indicação (LD, art. 13, $\S 1^{\circ}$, cc. art. 14). Protesto por indicação 
significa que o cartório efetuará o protesto com base nas indicações/informações fornecidas pelo credor, por exemplo, pelo canhoto de recebimento das mercadorias assinado, além de outros elementos constantes da nota fiscal-fatura, situação em que é dispensada a apresentação do título (exceção ao princípio da cartularidade).

Essa regra está alinhada com a Lei do Protesto, que em seu art. $8^{\circ}$, parágrafo único, dispõe que o Tabelionato de Protesto poderá recepcionar as indicações a protesto de duplicata mercantil e de prestação de serviço, por meio magnético ou de gravação eletrônica de dados. Soma-se a isso a autorização legal prevista pelo Código Civil de 2002, art. $889, \S 3^{\circ}$, combinado art. 903 . O primeiro dispositivo autoriza a emissão eletrônica de títulos de crédito. O segundo permite a aplicação supletiva das regras do Código Civil aos regramentos especiais dos demais títulos de crédito, senão houver contrariedade expressa.

Em análise do $\S 3^{\circ}$ do art. 889, Ligia Paula Pires Pinto posiciona-se no sentido de que a emissão e circulação por meio eletrônico se dá tanto para os títulos atípicos ou inominados trazidos pelo Código Civil, quanto para os títulos típicos previstos em legislação especial. ${ }^{10}$

Quanto à execução judicial da duplicata ou triplicata aceita, protestada ounão, a petição deve ser instruída com o título (LD, art. 15, I). Porém, para a execução judicial de "duplicata sem aceite" ou "duplicata não devolvida", será necessária a prova do protesto juntamente com o comprovante de entrega da mercadoria ou prestação de serviço a fim de instruir a petição (LD, art. 15, II).

Há tempos, a duplicata desprendeu-se das regras ordinárias previstas em sua norma em razão da realidade negocial, assumindo uma dinâmica influenciada pelo desenvolvimento da informática. Esse fato, em grande medida, acabou levando a duplicata a ser desmaterializada, transformando-se em simples registros eletromagnéticos, os quais são transmitidos pelo empresário à instituição financeira, ${ }^{11}$ quando da realização de operação de desconto bancário.

Fernando Netto Boiteux afirma que os empresários deixaram de emitir duplicatas em papel e passaram a emitir uma relação das duplicatas emitidas por meio eletrônico. Esta relação é conhecida como borderô, do qual constam os números das duplicatas, correspondendo tais números aos das respectivas notas fiscais-faturas. $\mathrm{O}$ borderô é remetido ao banco por via eletrônica (atualmente via internet, no passado por outros veículos como o disquete). Assim, o banco emite e encaminha aos sacados (devedores), para que efetuem o pagamento na rede bancária, um documento de cobrança

10 PINTO, Ligia Paula Pires. Títulos de crédito eletrônicos e assinatura digital: análise do art. $889, \S 3^{\circ}$ do Código Civil. In: PENTEADO, Mauro Rodrigues (coord.). Títulos de crédito: teoria geral e títulos atípicos em face do novo Código Civil, títulos de crédito eletrônico. São Paulo: Walmar, 2004. p. 196.

11 Nesse sentido, DE LUCCA, Newton. A cambial-extrato. p. 23 e ss. 
(boleto bancário) com os dados dos sacadores. Se determinado boleto deixar de ser pago, o banco comunica-se com o Tabelionato de Protesto também por via eletrônica e envia a indicação dos dados do título, ao invés do próprio título impresso em papel ou o seu respectivo boleto bancário, para se efetuar o protesto. O comprovante da entrega da mercadoria ou prestação de serviços é substituído por uma declaração do sacador de que tal documento encontra-se em sua posse, a fim de exonerar o banco de responsabilidade. ${ }^{12}$

A transferência dos créditos para o banco trata-se de um negócio denominado desconto bancário, que consiste na operação de recebimento antecipado dos valores de títulos de créditos não vencidos, o que é muito utilizado pelos empresários que vendem a crédito. A antecipação dos valores é feita por um banco, para o qual o comerciante transferiu os créditos. A princípio, a transmissão dos créditos deveria ser efetivada por endosso (ou excepcionalmente por cessão de crédito), mas a informática acabou por alterar essa formalidade.

Na operação de desconto, os valores antecipados dos títulos de crédito ficam sujeitos a um deságio, a fim de remunerar a instituição financeira por ter antecipado o valor; pelos seus custos de cobrança; e pelo risco de inadimplência assumido. Teoricamente, o risco poderá ser total quando não tiver direito de regresso contra quem lhe transmitiu o título, ou devolvê-lo; ou parcial, quando isso for possível. O risco vai influir na taxa de juros cobrada na operação.

Ao tempo do vencimento, o banco promove a cobrança do crédito mediante a expedição de boleto bancário, que não se trata de um título de crédito, mas sim um aviso de cobrança ao devedor que tem a facilidade de permitir sua quitação por meio da rede bancária física, caixas eletrônicos ou pela internet.

Neste caso, a duplicata em si apenas vai surgir quando houver inadimplemento do devedor. Na grande maioria das vezes há o adimplemento da obrigação, assim a duplicata tem a potencialidade de ser emitida, por isso a designação de duplicata virtual. ${ }^{13}$ Isso porque é um título cuja emissão é feita pelo credor.

Vale destacar que, a emissão e o pagamento de boletos bancários tornaramse uma prática corriqueira no comércio, ou seja, usos e costumes. Usos e costumes são práticas continuadas de determinados atos pelos agentes econômicos, que são aceitas pelos empresários como regras obrigatórias. Eles vigoram quando a lei não possui normas expressas para regular o assunto.

12 BOITEUX, Fernando Netto. Títulos de crédito: (em conformidade com o novo código civil). cit., p. 50-51.

13 FRONTINI, Paulo Salvador. Títulos de crédito e títulos circulatórios: que futuro a informática lhes reserva? Rol e funções à vista de sua crescente desmaterialiação. Revista dos Tribunais, São Paulo, n. 730, ago. 1996. p. 60 . 
No âmbito do STJ, em voto proferido como relatora do Recurso Especial n. 1024691/PR, após citar o artigo já referido de Paulo Salvador Frontini, a ministra Nancy Andrigui expressou em parte de voto:

Ementa: EXECUÇÃO DE TÍTULO EXTRAJUDICIAL. DUPLICATA VIRTUAL. PROTESTO POR INDICAÇÃO. BOLETO BANCÁRIO ACOMPANHADO DO COMPROVANTE DE RECEBIMENTO DAS MERCADORIAS. DESNECESSIDADE DE EXIBIÇÃO JUDICIAL DO TÍTULO DE CRÉDITO ORIGINAL. 1. As duplicatas virtuais - emitidas e recebidas por meio magnético ou de gravação eletrônica - podem ser protestadas por mera indicação, de modo que a exibição do título não é imprescindível para o ajuizamento da execução judicial. Lei n. 9.492/97. 2. Os boletos de cobrança bancária vinculados ao título virtual, devidamente acompanhados dos instrumentos de protesto por indicação e dos comprovantes de entrega da mercadoria ou da prestação dos serviços, suprem a ausência física do título cambiário eletrônico e constituem, em princípio, títulos executivos extrajudiciais. 3. Recurso especial a que se nega provimento.

Trecho do voto da Relatora: (...) "Os usos e costumes desempenham uma relevante função na demarcação do Direito Comercial. Atualmente, os hábitos mercantis não exigem a concretização das duplicatas, ou seja, a apresentação da cártula impressa em papel e seu encaminhamento ao sacado. É fundamental, portanto, considerar essa peculiaridade para a análise deste recurso especial, a fim de que seja alcançada solução capaz de adaptar a jurisprudência à realidade produzida pela introdução da informática na praxe mercantil - sem, contudo, desprezar os princípios gerais de Direito ou violar alguma prerrogativa das partes. É importante ter em vista, ainda, que a má interpretação da legislação aplicável às transações comerciais pode ser um sério obstáculo à agilidade negocial, de maneira a tornar a posição do Brasil no competitivo mercado internacional cada vez mais desvantajosa." STJ. RESP 1024691/PR. $3^{\text {a }}$ Turma. Relatora Min. Nancy Andrigui. DJe 12/04/2011.

Contudo, entendemos que a duplicata virtual é uma realidade amparada pelo ordenamento jurídico, pois, como analisado, o aceite não precisa ser necessariamente realizado no próprio título; o protesto pode ser feito eletronicamente por meio de indicação; e a legislação admite a execução de duplicata não aceita, desde que protestada, acompanhada do comprovante de entrega do produto (ou prestação de serviço) e sem que tenha havido recusa de aceite pelo sacado. 
Por último, Paulo Salvador Frontini aponta outro fator que afeta a dinâmica da duplicata, as vendas ao consumidor cujas operações quando feitas para pagamento a prazo utilizam-se da figura do cheque pré-datado ${ }^{14}$ [que embora não corresponda a uma ordem de pagamento à vista, como prevê a lei, é usual no comércio].

\section{Aspectos práticos e processuais}

Parece claro que, com o passar do tempo há uma forte tendência à substituição do papel por arquivos digitais. Isso tem acontecido no campo jurídico em várias searas, como já apontado, não passando imune a teoria geral dos títulos de crédito em especial os princípios da cartularidade e da literalidade.

A questão é saber se, em termos práticos, um arquivo digital tem condições de suportar os atos cambiários da mesma forma que o papel. Isso, pois, conforme a legislação em vigor, por exemplo, o saque, o aceite, o endosso e o aval são atos que devem ser praticados no corpo do título, na cártula, portanto.

Sobre o endosso e o aval, o Decreto n. 57.663/1966 - Lei Uniforme - LU -, assim dispõe: “Art. 13, primeira parte, da LU: O endosso deve ser escrito na letra ou numa folha liga a esta (anexo). Deve ser assinado pelo endossante. (...) Art. 31, primeira parte, da LU: O aval é escrito na própria letra ou numa folha anexa."

Teoricamente, a tecnologia da informação permitiria que os atos cambiários fossem praticados diretamente num arquivo digital que seria o título de crédito em si, especialmente pelo uso da assinatura digital e certificação eletrônica, que trariam segurança quanto ao teor dos atos, à luz da Medida Provisória n. 2.200-2/2001 criou a Infraestrutura de Chaves Públicas Brasileira - ICP-BRASIL.

Isso poderia ser reconhecido pela doutrina e jurisprudência, seja como usos e costumes mercantis, seja pela aplicação do art. 903 do Código Civil: "Salvo disposição diversa em lei especial, regem-se os títulos de crédito pelo disposto neste Código."

Esse dispositivo deve ser combinado com a autorização prevista no $\S 3^{\circ}$ do art. 889: “O título de crédito poderá ser emitido a partir dos caracteres criados em computador ou meio técnico equivalente e que constem da escrituração do emitente, observados os requisitos mínimos previstos neste código."

Feita essa combinação de dispositivos, alinhada ao uso de tecnologia com segurança, os títulos de crédito poderiam efetivamente assumir a figura de um título eletrônico, cuja documentalidade não seria num papel, mas sim num suporte digital, o qual poderia ser, com o uso da tecnologia, sacado, aceitado, endossado e avalisado.

14 FRONTINI, Paulo Salvador. Títulos de crédito e títulos circulatórios: que futuro a informática lhes reserva? Rol e funções à vista de sua crescente desmaterialiação. cit., p. 60 . 
No entanto, imagine a situação em que um título eletrônico receberia várias assinaturas (digitais) no mesmo documento (arquivo), consistindo cada qual uma manifestação de vontade, seja sacador, avalistas ou endossantes. Todavia, isso talvez não seja tão simples e prático como nos títulos físicos (cartularizados), mas que é um obstáculo que pode ser atenuado com o tempo em razão do avanço da tecnologia. ${ }^{15}$

Quanto ao aspecto processual, o CPC - Código de Processo Civil -, art. 585, inc. I, ao enumerar os títulos de crédito que podem ser objeto de execução judicial, entre eles a duplicata, o cheque e a nota promissória, não exige que o título esteja suportado por papel.

No máximo, o que exige é que o título seja derivado de obrigação certa, líquida e exigível, conforme o seu art. 586: "A execução para cobrança de crédito fundarse-á sempre em título de obrigação certa, líquida e exigível."

Considerando que o teor do arquivo digital estará assegurado pelo uso da assinatura digital e certificação eletrônica, se o título contiver uma obrigação inquestionável quanto à sua existência (certa), com valor determinado e corretamente expresso (líquido) e vencido (exigível), ele poderá ser objeto de execução judicial.

E mais, o art. 614, inc. I, do CPC, ao tratar da execução judicial não exige que o suporte do título seja o papel. Art. 614: "Cumpre ao credor, ao requerer a execução, pedir a citação do devedor e instruir a petição inicial: I - com o título executivo extrajudicial".

Além disso, até o processo judicial em si, que nos últimos séculos esteve suportado pelo papel, no Brasil tem se inclinado para o suporte eletrônico, haja vista a Lei n. 11.419/2006, cujo objetivo é a informatização do processo judicial.

Para efeitos processuais a Lei n. 11.419/2006 prevê em seu art. 11 que o documento eletrônico é expressamente admissível como meio de prova. A força probante deste tipo de documento passa a equivaler à do documento tradicional quando este apresentar determinados requisitos.

Conforme dispõe o caput do art. 11 da Lei n. 11.419/2006: “Os documentos produzidos eletronicamente e juntados aos autos do processo eletrônico com garantia da origem e de seu signatário, na forma estabelecida nesta Lei, serão considerados originais para todos os efeitos legais."

Esse dispositivo nos aproxima do que foi disciplinado pelo Código Civil francês, que no seu art. 1.316-3 equipara o escrito em suporte eletrônico ao escrito em papel para fins probatórios.

15 No mesmo sentido, CASTRO, Raphael Velly de. Notas sobre a circulação e a literalidade nos títulos de crédito eletrônicos. In: PENTEADO, Mauro Rodrigues (Coord.). Títulos de crédito: teoria geral e títulos atípicos em face do novo Código Civil, títulos de crédito eletrônico. São Paulo: Walmar, 2004. p. 399. 
Dessa forma, se não fossem os dispositivos legais autorizadores da execução de um título emitido eletronicamente, ao credor restaria ainda, se for o caso, ajuizar ação monitória, prevista nos arts. 1.102-A a 1.102-C do Código de Processo Civil. Essa ação de conhecimento tem por objeto efetuar a constituição de um título executivo a partir de uma prova escrita que não tenha eficácia executiva. Neste caso, utilizar-se-ão os documentos escritos que comprovam o direito de crédito do interessado.

\section{Conclusão}

Diante do exposto, podemos concluir que a emissão de títulos eletrônicos é possível por disposição expressa do art. 889, $\S 3^{\circ}$, do Código Civil, sendo que, teoricamente, essa possibilidade é dada a qualquer título de crédito, mas especialmente a duplicata do ponto de vista prático. Isso porque as respectivas normas cambiárias não vedam tal possibilidade, sem prejuízo do que dispõe o art. 903 do Código Civil, ao dispor que as normas deste Código em matéria de títulos de crédito são aplicáveis a títulos disciplinas por lei especiais desde que não as afronte, o que não é o caso.

Utilizando-se de assinatura digital e certificação eletrônica, em tese, é possível realizar atos cambiários, como o saque, o aceite, o endosso e o aval. O título emitido eletronicamente (com uso da assinatura digital) circulará eletronicamente para o banco, que cobrará eletronicamente. Assim, saque, aceite, endosso e aval são possíveis em um título emitido eletronicamente, pois serão apostos no próprio título atendendo às determinações da Lei Uniforme, no entanto, serão apostos em um arquivo eletrônico mediante o uso de assinatura digital e certificação eletrônica.

Tudo isso, em tese, permite que os atos cambiários inerentes aos títulos de crédito possam ser praticados utilizando-se deste ferramental tecnológico, como o saque, o aceite, o aval e o endosso, ainda que talvez não seja muito prático aos empresários, em especial quanto à circulação do título.

O título de crédito consiste em uma declaração unilateral de vontade, sendo que não há nenhuma norma que exija que essa declaração deva ser materializada obrigatoriamente em papel. A cártula sempre trouxe segurança para o cumprimento da obrigação via execução judicial, mas atualmente isso é perfeitamente possível e admitido pela legislação, mediante suporte eletrônico.

Além disso, o art. 887 expressa a palavra "documento", não "cártula"; e que o título somente produzirá efeitos se preencher os requisitos da lei. Logo, um título emitido eletronicamente (documento eletrônico) poderá ser tido como título de crédito desde que respeite as regras da sua norma regente. Sem dizer que as leis cambiárias quando estabelecem requisitos formais para um título de crédito não menciona a necessidade de cártula (papel). 
Quanto à executividade do título, ele apenas deixou o suporte em papel para utilizar o suporte eletrônico, sendo apenas uma questão de prova. Deve ser observado aqui que até o processo judicial poderá ser digital, conforme estabelece a Lei n. 11.419/2006, que disciplina a informatização do processo judicial.

Caso não haja avanço jurídico na aceitação de títulos emitidos eletronicamente, seja por posição doutrinária e jurisprudencial, seja por reforma legal, os títulos de crédito podem acabar não circulando fisicamente, mas continuarão sendo cobrados por via bancária, ou mesmo por factoring, restando a eles a finalidade de instrução para eventual execução judicial ou protesto. Mas acreditamos também ser possível a continuidade da circulação dos títulos de crédito em razão da tecnologia atual (e a ser desenvolvida), em especial pelo uso de assinatura digital e certificação eletrônica. Dependerá da vontade dos agentes econômicos em razão da maior agilidade ou não no tráfico mercantil.

Até porque, imagine a situação em que um título eletrônico receberia várias assinaturas digitais no mesmo documento-arquivo, consistindo cada qual uma manifestação de vontade, seja sacador, avalistas ou endossantes. Eventualmente esse fato não se apresente de forma tão simples e prático como nos títulos físicos (cartularizados), todavia é um obstáculo que pode ser atenuado com o tempo em razão do avanço da tecnologia. Também, para a transmissão com uso da assinatura digital o destinatário precisaria estar com a chave pública para decriptografar o documento, o que pode ser algo inviável na prática mercantil.

Como seria a tradição/circulação eletrônica? A tradição física de bem corpóreo implica em o objeto sair do campo de domínio de uma pessoa e adentrar no de outra. No campo digital não, pois o imaterial permite a duplicação do bem, se ao transferilo a outrem o arquivo continuar com quem o transferiu, o que poderia permitir outras circulações a terceiros de boa-fé. Solução possível seria a criação de título em nuvem em que ele ficasse custodiado no servidor de uma entidade, a qual receberia a ordem do credor, mediante assinatura digital, para transferir a titularidade a um terceiro, que passaria ser o novo credor. Isso, teoricamente, impediria títulos eletrônicos ao portador.

Essa entidade custodiadora poderia funcionar como as Centrais de Registro, Custódia, Compensação e Liquidação de títulos escriturais, a exemplo, da SELIC e da CETIP. SELIC - Sistema Especial de Liquidação e de Custódia - é o depositário central dos títulos emitidos pelo Tesouro Nacional e pelo Banco Central do Brasil e nessa condição processa, relativamente a esses títulos, a emissão, o resgate, o pagamento dos juros e a custódia. Todos os títulos são escriturais, isto é, emitidos exclusivamente na forma eletrônica. O sistema é gerido pelo Banco Central. Cetip S.A. - Mercados Organizados é uma companhia de capital aberto que oferece serviços de registro, central depositária, negociação e liquidação de ativos, títulos e valores mobiliários. O próprio BACEN poderia 
ser o custodiador, sendo que a titularidade dos títulos poderia ser consultada mediante o número do CNPJ ou CPF.

Assim, como na década de 1960, nos Estados Unidos, buscou-se extinguir os certificados de ações, principalmente das grandes empresas, tendo em vista o volume de ações negociadas na Bolsa de Valores de Nova York, a cártula, na qual estaria mencionado o direito do titular, após tantas facilidades promovidas à atividade negocial durante séculos, passou a atrapalhar. ${ }^{16}$ Esse fato desaguou nas ações escriturais, que acabaram se tornando regra geral, inclusive em território nacional. Logo, nos parece que o caminho para os títulos de crédito seja algo parecido, ou seja, a substituição de sua materialização em papel pelo suporte eletrônico.

Contudo, temos legislação e tecnologia para criação e utilização de títulos emitidos eletronicamente, mas, de qualquer forma, é preciso repensar a teoria geral dos títulos de crédito, em especial o princípio da cartularidade, haja vista que cada vez mais os títulos até então materializados em papel tender a diminuir, notadamente pelo avanço das formas de pagamento eletrônicas, como o cartão de débito e o cartão de crédito.

Londrina, 27 de maio de 2014.

Referências

ABRÃO, Carlos Henrique. Cartões de crédito e débito. 2. ed. São Paulo: Atlas, 2011.

ABRÃO, Nelson. Cibernética e títulos de crédito. Revista de Direito Mercantil, Industrial, Econômico e Financeiro, São Paulo, n. 19. 1975.

ASCARELLI, Tullio. Teoria geral dos títulos de crédito. 2. ed. São Paulo: Saraiva, 1969.

BOITEUX, Fernando Netto. Títulos de crédito: (em conformidade com o novo código civil). São Paulo: Dialética, 2002.

BULGARELLI, Waldirio. Títulos de crédito. 2. ed. São Paulo: Atlas, 1982.

CASTRO, Raphael Velly de. "Notas sobre a circulação e a literalidade nos títulos de crédito eletrônicos”. In: PENTEADO, Mauro Rodrigues (Coord.). Títulos de crédito: teoria geral e títulos atípicos em face do novo Código Civil, títulos de crédito eletrônico. São Paulo: Walmar, 2004.

COMPARATO, Fábio Konder. Ensaios e pareceres de direito empresarial. Rio de Janeiro: Forense, 1978.

COSTA, Wille Duarte. Títulos de crédito. 2. ed. Belo Horizonte: Del Rey, 2006.

${ }_{16}$ BOITEUX, Fernando Netto. Títulos de crédito: (em conformidade com o novo código civil). cit., p. 49. 
DE LUCCA, Newton. Aspectos da teoria geral dos títulos de crédito. São Paulo: Pioneira, 1979. . A cambial-extrato. São Paulo: Revista dos Tribunais, 1985.

FRONTINI, Paulo Salvador. Títulos de crédito e títulos circulatórios: que futuro a informática lhes reserva? Rol e funções à vista de sua crescente desmaterialiação. Revista dos Tribunais, São Paulo, n. 730 , ago. 1996.

GARDINO, Adriana Valéria Pugliesi. Títulos de crédito eletrônicos: noções gerais e aspectos processsuais. In: PENTEADO, Mauro Rodrigues (Coord.). Títulos de crédito: teoria geral e títulos atípicos em face do novo Código Civil, títulos de crédito eletrônico. São Paulo: Walmar, 2004.

PINTO, Ligia Paula Pires. Títulos de crédito eletrônicos e assinatura digital: análise do art. 889, § $3^{\circ}$ do Código Civil. In: PENTEADO, Mauro Rodrigues (Coord.). Títulos de crédito: teoria geral e títulos atípicos em face do novo Código Civil, títulos de crédito eletrônico. São Paulo: Walmar, 2004.

TEIXEIRA, Tarcisio. Curso de direito e processo eletrônico: doutrina, jurisprudência e prática. São Paulo: Saraiva, 2013.

. Direito empresarial sistematizado: doutrina, jurisprudência e prática. 3. ed. São Paulo: Saraiva, 2014. 